\title{
Passive Strategies of Naturally Ventilated Residential Houses in the Equatorial Humid Tropics
}

\author{
Harimi Djamila
}

\begin{abstract}
The thermal performance of any house depends on the climatic conditions surrounded the buildings. The aim of this study is to investigate the available strategies for building passive design. This is while making the building comfortable and efficient. Mahoney tables, bioclimatic chart and Climate Consultant software were used to analyze the available strategies in improving the indoor thermal performance of the building for occupants' thermal comfort. Kota Kinabalu city (Malaysia) and Bandar Seri Begawan (Brunei) are the selected locations in this study. The results showed that all the methods agreed that ventilation is the best approach for passive cooling. Many recommended passive strategies for indoor cooling were suggested and discussed in this article. Overall, thermal comfort of the occupants was not achievable all the time. In the humid tropics heat gain is also not recommended all year round.
\end{abstract}

Index Terms-Malaysia, tropical humid climate, passive design, residential buildings.

\section{INTRODUCTION}

The thermal performance of any house depends on the climatic conditions surrounded the buildings. Outdoor environment conditions control the indoor thermal behavior of the building. This in turn affects the indoor thermal conditions. The thermal resistance of the walls and the particular design of any house are vital to the success of the indoor thermal environment. Outdoor air temperature and relative humidity are among the most known climatic parameters used for climatic building design. Wind and solar radiation are also required for addressing the passive thermal performance of a house. To clarify the impact of air temperature, relative humidity and other climatic parameters in relation to building design, several building thermal design tools are available. The purpose of such tools is for making the building comfortable and efficient.

Mahoney method is well known procedure in providing initial design recommendations for climatic performance of any building. Bioclimatic chart is also useful in describing the microclimate of a location by providing strategies for building thermal design. The method reveals the portion of a typical year that the occupants will be comfortable with a determined cooling or heating strategy. It also helps in identifying when the active cooling will be required.

These basic tools are important for understanding the required passive cooling strategies with the appropriate building material. This is primordial when the building and

Manuscript received May 26, 2016; revised August 21, 2016.

Harimi Djamila is with the Faculty of Engineering, Universiti Malaysia Sabah, Kota Kinabalu, 88400, Malaysia (e-mail: harimidjamila@gmail.com). also the occupants are subjected to specific climate without the usage of air-conditioning.

The purpose of this research is about investigating passive cooling strategies in the equatorial humid tropics.

\section{METHODOLOGY}

In this investigation, Mahoney method [1], bioclimatic chart and Climate Consultant Software version 6 were used to characterize the recommended passive methods in the equatorial humid tropics. Kota Kinabalu city which is located in East Malaysia was firstly chosen for this investigation. Mahoney method was applied. The method requires only monthly climatic air temperature, relative humidity and precipitation. For better interpretation of possible passive cooling strategies in the humid tropics, Climate Consultant software was also used. The hourly climatic data of Kota Kinabalu city were not available. Therefore, Bandar Seri Begawan location was selected to investigate the impact of hourly outdoor climatic parameters on passive design. This is by using Climate Consultant Software. This location was carefully selected. It is close to Kota Kinabalu city. The two locations are subjected to tropical equatorial climate. Further, both are located near the sea. Fig. 1 shows both locations.

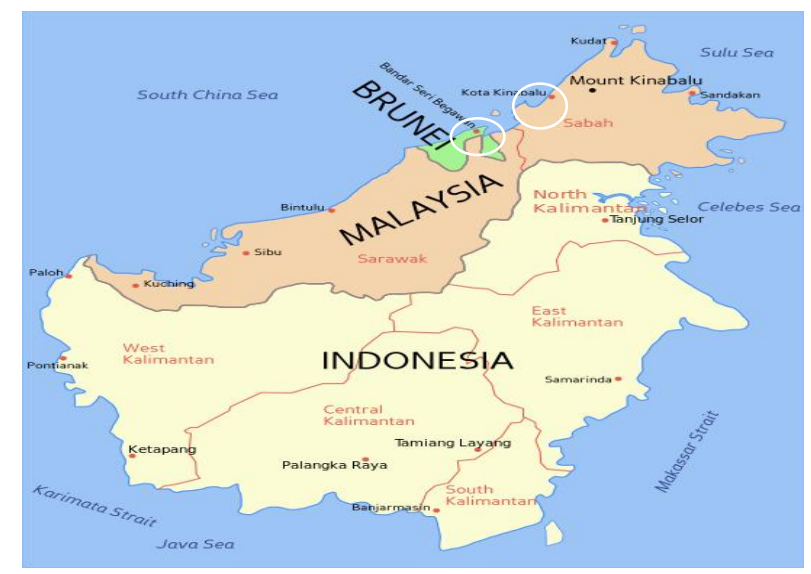

Fig. 1. Map of Borneo (light yellow = Indonesia, light orange = Malaysia, green $=$ Brunei). Author: Mortadelo2005.

For a comparison between the climates of the two locations, the outdoor monthly temperatures and relative humidity were firstly plotted (Fig. 2 and 3). For Kota Kinabalu case study, the collected data was from 1968 to 2003. It was used by estimating the average value from the monthly mean maximum and the mean minimum temperatures of Kota Kinabalu. However, the collected data for the mean maximum and minimum relative humidity were from 1997 to 2002. The monthly rainfall data were from 1991 to 2003. All data were collected from Sabah Meteorological station. The 
calculated annual average temperature was about $27.48^{\circ} \mathrm{C}$. The mean temperatures were estimated as the average of the maximum and the minimum monthly temperatures. For the case of Bandar Seri Begawan, the data were collected from EnergyPlus Weather file from the US Department of Energy's EnergyPlus site. The monthly outdoor air temperatures and relative humidity in Kota Kinabalu and Bandar Seri Begawan are plotted in Fig. 2 and Fig. 3 respectively. The maximum monthly difference between the two locations was no more than $1.6^{\circ} \mathrm{C}$. The difference in term of annual average temperature was less than $1^{0} \mathrm{C}$. The annual average air temperature for Kota Kinabalu was $27.47^{\circ} \mathrm{C}$ and $26.58^{\circ} \mathrm{C}$ for Bandar Seri Begawan. It is obvious that both locations are subjected to similar climate. The noted differences might be due to the microclimate of the location, accuracy of the instrument used and geographic differences or other reasons. For relative humidity, both locations were subjected to no less than $79 \%$. The monthly relative humidity was mostly above $80 \%$. The annual average relative humidity for Kota Kinabalu was $81.5 \%$ and $83.4 \%$ for Bandar Seri Begawan.

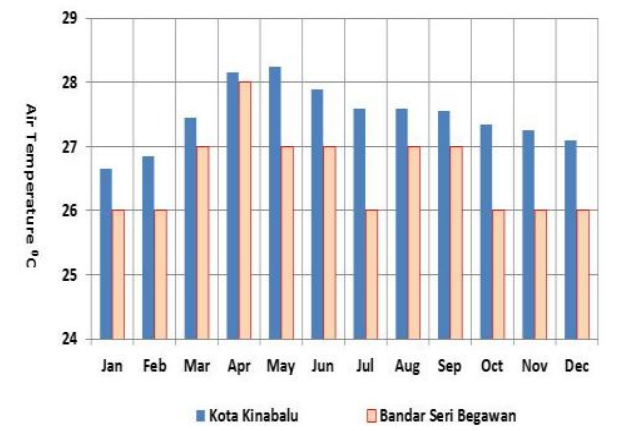

Fig. 2. Monthly outdoor air temperatures in Kota Kinabalu and Bandar Seri Begawan.

\section{MAHONEY TABLES}

Based on the climatic data of Kota Kinabalu, series of tables called Mahoney tables were used to diagnosis Kota Kinabalu climate for design recommendations. The required steps are well outlined in [1].

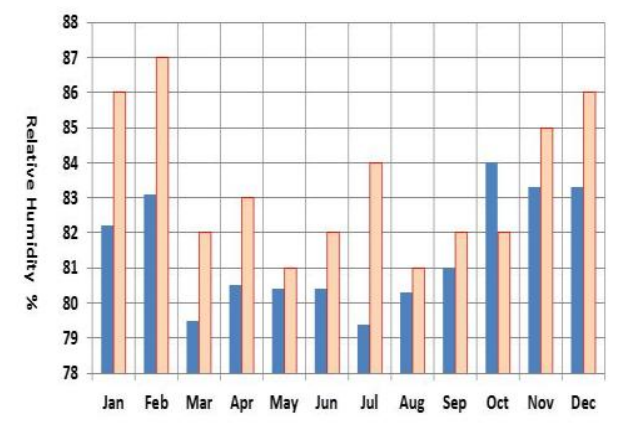

\[ \text { Kota Kinabalu } \]
Fig. 3. Meandar Seri Begawan
$\square$ Butdoor relative humidity in Kota Kinabalu and Bandar Seri Begawan.

Table I was utilized to assemble the monthly mean maximum and minimum temperatures, the annual mean temperature, and the annual mean temperature range. The annual mean temperature (AMT) was estimated from Eq. 1

$$
A M T=\left(M_{\max t}+M_{\min t}\right) / 2
$$

where, $M_{\max t t}$ is the mean maximum temperature of the twelve maxima $\left({ }^{0} \mathrm{C}\right) . \mathrm{M}_{\min \mathrm{tt}}$ is the mean minimum temperature of the twelve minima $\left({ }^{0} \mathrm{C}\right)$. The annual mean range ( $A M R$ ) was estimated from Eq.2.

$$
A M R=M_{\max t t}-M_{\min t t}
$$

The relative humidity values of Kota Kinabalu are summarized in Table II. The humidity groups were derived from the Mahoney classification. The Mahoney classification for average relative humidity $(\mathrm{RH})$ is given below:

- Below 30\% = Group 1

- $30 \%-50 \%=$ Group 2

- $50 \%-70 \%=$ Group 3

- Above $70 \%=$ Group 4

The rainfall data utilized for this analysis are summarized in Table III. The diagnosis of Kota Kinabalu climate using Mahoney table is listed in Table IV.

An analysis of the climatic data of Kota Kinabalu with Mahoney tables showed that the ambient temperatures were always above the comfort zone. It is apparent from the table that the comfort limit is similar all year round. It varied from 22 to $27^{\circ} \mathrm{C}$ during the daytime and 17 to $21^{\circ} \mathrm{C}$ during the night time. The maximum temperature difference between the monthly mean maximum and the upper day comfort was $5.2^{0} \mathrm{C}$. This was found during April and May. However the maximum temperature difference between the monthly mean minimum and the upper night comfort was $3.3^{\circ} \mathrm{C}$ on May. The difference was reduced to $1.9^{\circ} \mathrm{C}$ on January. The suggested comfort temperatures seems to be very low when considering recent field studies conducted in the equatorial humid tropics such Malaysia and Singapore [2], [3]. It is important to mention that currently, little is known about thermal comfort during night time. It is obvious that thermal comfort during night time requires further investigations all over the world.

Based on Mahoney Tables recommendations, passive techniques in Kota Kinabalu should minimize the solar storage and maximize the ventilation. This is by proper planning. The building and openings should be oriented north and south long axis (East-West) with open spacing for breeze penetration to reduce the unwanted solar radiation. This is because unlike opaque wall and roof surfaces, glass transmits as much as $85 \%$ of the incident solar radiation instantaneously. North and south is considered the best orientation of the house with regard to solar radiation [4]

Permanent air movement was also recommended when planning and constructing building. The reason is to provide good air circulation. Additional recommendation is this; rooms should be single banked.

\section{IV. *H: MEANS Hot AND ABOve THE COMFORT LIMIT}

From Mahoney method, the openings should also be $40-80 \%$ of the wall area at body height side. It should be well protected from direct sunlight. Since the narrow diurnal temperature range seldom fall below comfort level, low thermal capacity with short time-lag for walls were also recommended in the Mahoney tables. The present author did 
not fully agree with the last recommendation. For instance if the building will be only used during daytime; high thermal capacity of walls will be certainly recommended. This is the case of office building. In residential buildings, the situation might be different. Light walls are mostly recommended during night time to minimize the stored heat from walls. This is because the buildings are not located in the jungles or surrounded by trees as in the past. Light roofs with reflective surface should be ensured under Kota Kinabalu climate. Protection from heavy rain is necessary and adequate rainwater drainage was also recommended.

TABLE I: TEMPERATURE DATA OF KotA KinABALU $\left({ }^{0} \mathrm{C}\right)$

\begin{tabular}{|c|c|c|c|c|c|c|c|c|c|c|c|c|c|c|}
\hline Temp. & $\mathrm{J}$ & $\mathrm{F}$ & M & A & M & $\mathrm{J}$ & $\mathrm{J}$ & A & $S$ & $\mathrm{O}$ & $\mathrm{N}$ & $\mathrm{D}$ & High & AMT \\
\hline $\begin{array}{l}\text { Monthly Air mean } \\
\text { max. }\end{array}$ & 30.4 & 30.7 & 31.5 & 32.2 & 32.2 & 31.8 & 31.5 & 31.5 & 31.4 & 31.1 & 31.0 & 30.8 & 32.2 & 27.6 \\
\hline Monthly mean min. & 22.9 & 23.0 & 23.4 & 24.1 & 24.3 & 24.0 & 23.7 & 23.7 & 23.7 & 23.6 & 23.5 & 23.4 & 22.9 & 9.3 \\
\hline Monthly mean range & 7.4 & 7.6 & 8.1 & 8.0 & 7.8 & 7.8 & 7.8 & 7.8 & 7.7 & 7.5 & 7.5 & 7.5 & Low & AMR \\
\hline
\end{tabular}

TABLE II: RELATIVE HUMIDITY DATA OF KOTA KINABALU (\%)

\begin{tabular}{lcccccccccccc}
\hline \hline Relative humidity \% & $\mathrm{J}$ & $\mathrm{F}$ & $\mathrm{M}$ & $\mathrm{A}$ & $\mathrm{M}$ & $\mathrm{J}$ & $\mathrm{J}$ & $\mathrm{A}$ & $\mathrm{S}$ & $\mathrm{O}$ & $\mathrm{N}$ & $\mathrm{D}$ \\
\hline \hline Monthly mean max (A.M.) & 89.6 & 89.8 & 85.6 & 88.0 & 88.0 & 88.6 & 86.0 & 88.9 & 88.2 & 91.0 & 89.2 & 89.9 \\
Monthly mean min (P.M.) & 74.8 & 76.5 & 73.4 & 72.9 & 72.8 & 72.2 & 72.9 & 71.6 & 73.7 & 76.9 & 77.4 & 76.7 \\
Average & 82.2 & 83.1 & 79.5 & 80.5 & 80.4 & 80.4 & 79.4 & 80.3 & 81.0 & 84.0 & 83.3 & 83.3 \\
Humidity group & 4 & 4 & 4 & 4 & 4 & 4 & 4 & 4 & 4 & 4 & 4 & 4 \\
\hline \hline
\end{tabular}

TABLE III: RAINFALLS OF KOTA KINABALU (MM)

\begin{tabular}{|c|c|c|c|c|c|c|c|c|c|c|c|c|}
\hline $\mathrm{J}$ & $\mathrm{F}$ & $\mathrm{M}$ & A & $\mathrm{M}$ & $\mathrm{J}$ & $\mathrm{J}$ & A & $\mathrm{S}$ & $\mathrm{O}$ & $\mathrm{N}$ & $\mathrm{D}$ & Total \\
\hline 97.2 & 66.3 & 95 & 125.9 & 170.7 & 237.4 & 261.1 & 288.1 & 270.9 & 404.9 & 267.9 & 245.6 & 2531.8 \\
\hline
\end{tabular}

TABLE IV: MAHONEY DiAgNOSIS (KotA KinABALU)

\begin{tabular}{|c|c|c|c|c|c|c|c|c|c|c|c|c|c|c|}
\hline Diagnoses ${ }^{\circ} \mathrm{C}$ & $\mathrm{J}$ & $\mathrm{F}$ & $\mathrm{M}$ & $\mathrm{A}$ & $\mathrm{M}$ & $\mathrm{J}$ & $\mathrm{J}$ & $\mathrm{A}$ & $\mathrm{S}$ & $\mathrm{O}$ & $\mathrm{N}$ & $\mathrm{D}$ & & \\
\hline Monthly mean max. & 30.4 & 30.7 & 31.5 & 32.2 & 32.2 & 31.8 & 31.5 & 31.5 & 31.4 & 31.1 & 31.0 & 30.8 & 27.6 & AMT \\
\hline Day comfort: Upper & 27 & 27 & 27 & 27 & 27 & 27 & 27 & 27 & 27 & 27 & 27 & 27 & & \\
\hline Lower & 22 & 22 & 22 & 22 & 22 & 22 & 22 & 22 & 22 & 22 & 22 & 22 & & \\
\hline Monthly mean min. & 22.9 & 23.0 & 23.4 & 24.1 & 24.3 & 24.0 & 23.7 & 23.7 & 23.7 & 23.6 & 23.5 & 23.4 & & \\
\hline Night comfort: Upper & 21 & 21 & 21 & 21 & 21 & 21 & 21 & 21 & 21 & 21 & 21 & 21 & & \\
\hline $\begin{array}{r}\text { Lower } \\
\end{array}$ & 17 & 17 & 17 & 17 & 17 & 17 & 17 & 17 & 17 & 17 & 17 & 17 & & \\
\hline Thermal stress: day & $\mathrm{H}^{*}$ & $\mathrm{H}^{*}$ & $\mathrm{H}^{*}$ & $\mathrm{H}^{*}$ & $\mathrm{H}^{*}$ & $\mathrm{H}^{*}$ & $\mathrm{H}^{*}$ & $\mathrm{H}^{*}$ & $\mathrm{H}^{*}$ & $\mathrm{H}^{*}$ & $\mathrm{H}^{*}$ & $\mathrm{H}^{*}$ & & \\
\hline \begin{tabular}{|r|} 
Night \\
\end{tabular} & $\mathrm{H}^{*}$ & $\mathrm{H}^{*}$ & $\mathrm{H}^{*}$ & $\mathrm{H}^{*}$ & $\mathrm{H}^{*}$ & $\mathrm{H}^{*}$ & $\mathrm{H}^{*}$ & $\mathrm{H}^{*}$ & $\mathrm{H}^{*}$ & $\mathrm{H}^{*}$ & $\mathrm{H}^{*}$ & $\mathrm{H}^{*}$ & & \\
\hline
\end{tabular}

\section{BIOCLIMATIC CHART}

Bioclimatic method is important in the prediction of the potential of passive design strategies to maintain thermal for energy efficient built environment [5]. The climatic data used in the previous section were plotted in the bioclimatic chart as described by Brown [6]. The plotted results are shown in Fig. 4. The plotted lines of relative humidity and temperature in Fig. 4 are outside the suggested comfort zone for the whole year. It indicates that ventilation should be considered for this type of climatic condition. This was recommended in several references such in [7].

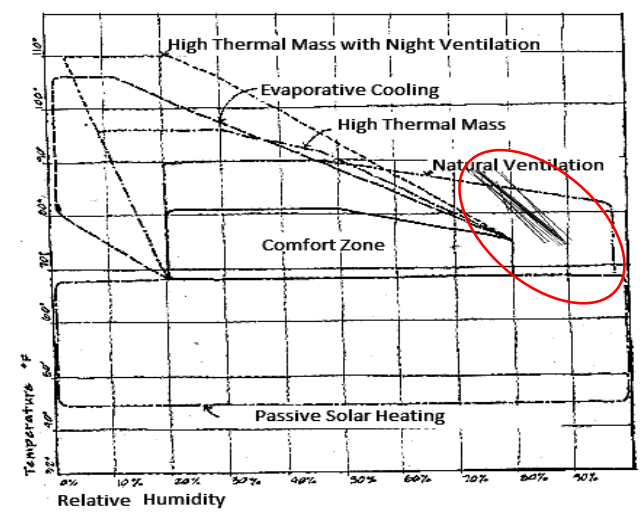

Fig, 4. Bioclimatic chart of Kota Kinabalu (Malaysia).
According to the present author own observation and also backed by references, the elevation of the house above the ground helps to catch stronger winds [8]. Further the wind is usually cool near the ground than at high elevation above the ground. This strategy was widely used in Malaysian houses. It was also used to protect the house from the floods during rainy seasons. High ceiling also was used in Malay traditional Houses. This is to allow hot air to rise high and above the occupants, so that the indoor thermal environment will be perceived comfortable. It is important to emphasis that natural ventilation is not only very important for cooling purpose but it is also essential for humidity removal [9] and for thermal comfort.

A study in a tropical humid region showed that a higher air speed is not always necessary for improving the indoor thermal condition. The authors also reported that balcony and most window configurations and interior division may affect the indoor thermal condition. This is important during sunny hot days, the wind speed will be most likely very weak [10]. Another possible strategy is to build the house when possible on a hill [11]. The reader may refer to [8] for additional useful recommendations.

It might be of interest to determine the comfort range from the adaptive thermal comfort according to ASHRAE 55 [12]. This might be applied for an initial checking. This is because 
local thermal comfort standard based on local case studies are more appropriate to be used for such analysis. However, due to lack of thermal comfort standard for residential buildings in Malaysia, the ASHRAE 55 was considered for this study when using the Climate Consultant Software. It is a better alternative compared with the comfort range suggested in Mahoney tables. It might be important to mention that a large scale investigation on thermal comfort was conducted in Kota Kinabalu. The comfort temperature was found to be $30^{\circ} \mathrm{C}$ [3]. This might be used when considering passive cooling strategies in the humid tropics of Kota Kinabalu.

\section{Climate Consultant}

A software tool was further used in this article to investigate the effect of climate on passive cooling strategies in the equatorial humid tropics. The procedure in this section is slightly more advanced than the Mahoney tables but the software is friendly to use. In this section, the analysis was made from hourly climatic data using this software. In the analysis, we also included the ASHRAE adaptive thermal comfort model. This is prior providing the recommendations. Therefore, the software is better than the comfort range suggested in Mahoney Tables. However, due to the lack of hourly climatic date in Kota Kinabalu city, Bandar Seri Begawan was selected in this analysis. Fig. 5 shows the thermal comfort assessment in Bandar Seri Begwan, Brunei. ASHRAE 55 approach of the adaptive method was selected.

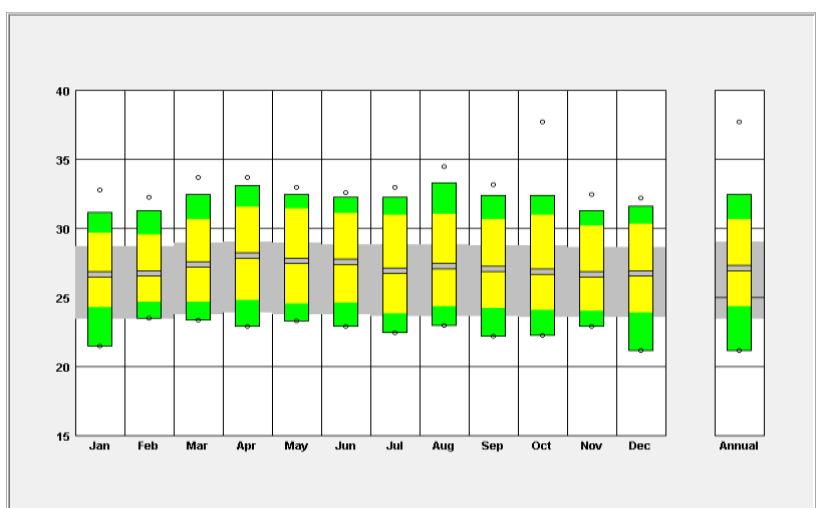

Fig. 5. Thermal comfort assessment in Bandar Seri Begwan, Brunei (4.930, $\left.114.93^{0}\right)$

A close observation in Fig. 5 revealed that the occupants in that location may not always be comfortable. The comfort range is colored grey. In this study, the selected acceptability limits is $90 \%$.

Fig. 6 shows the monthly dry bulb temperature in Bandar Seri Begwan, Brunei. Based on Monthly dry bulb temperature; the red color refers to the outdoor temperature range of 24 to $30^{\circ} \mathrm{C}$. Similar situation is expected in Kota Kinabalu. This is because the outdoor monthly temperature is also within that range.

It is of special interest to analyze the daily dry bulb temperature in Bandar Seri Begwan, Brunei. The plotted results are in Fig. 7.

The red color refers to the indoor temperature from 24 to $30^{\circ} \mathrm{C}$. The light green color refers to the range of indoor temperature from 20 to $24^{\circ} \mathrm{C}$. The obtained results revealed that $96 \%$ of the time, the indoor temperature was within 24 to $30^{\circ} \mathrm{C}$. Only $4 \%$ of the time, the temperature was 20 to $24^{\circ} \mathrm{C}$. This is likely expected in Kota Kinabalu. In a nutshell, for both locations, the daily range might be assumed from 24 to $30^{\circ} \mathrm{C}$. Finally, the bioclimatic chart for Bandar Seri Begwan was generated. The results are illustrated in Fig. 8.

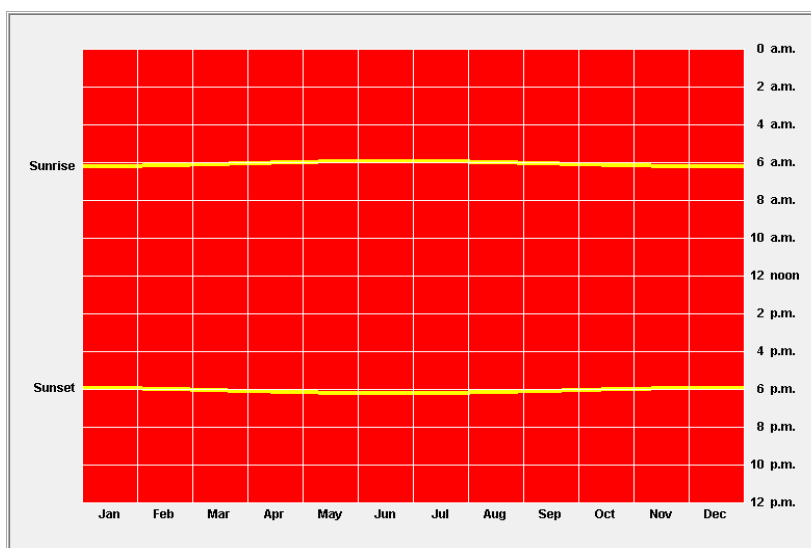

Fig. 6. Monthly dry bulb temperature in Bandar Seri Begwan, Brunei.

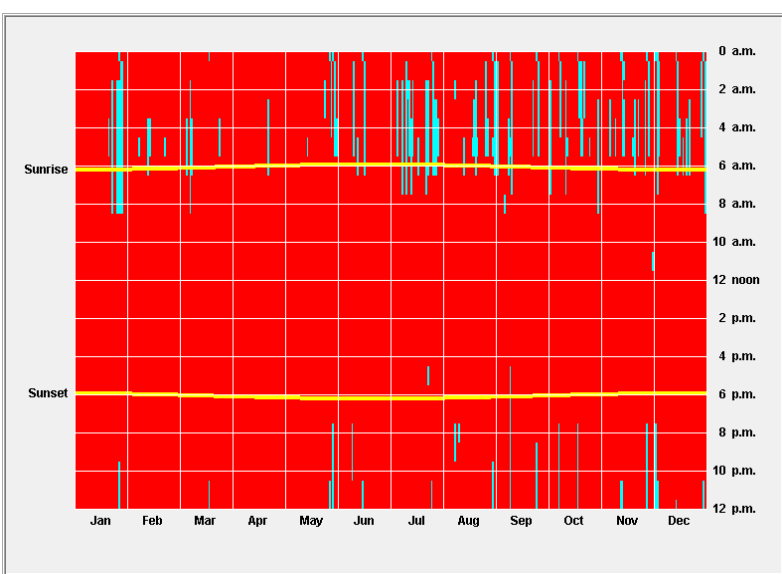

Fig. 7. Daily dry bulb temperature in Bandar Seri Begwan, Brunei.

The green color illustrates the indoor comfort temperature. Red is when the indoor temperature is uncomfortable. The obtained result revealed that $64 \%$ the indoor temperature was comfortable but $36 \%$ was not. This is when considering the ventilation. According to the Climate Consultant software; 5636 out of 8760 hours will be expected to be comfortable. This is by using the adaptive comfort ventilation as design strategies from January to December. The ventilation strategy is widely known to be the best strategy in the equatorial humid tropics such the case of Malaysia and Singapore. This is in agreement as well with the Mahoney table recommendations.

Given that cross ventilation is recommended in the humid tropics, it has also been recommended that door and window openings to be on opposite sides of building. This is by ensuring larger openings facing up-wind if possible. Additionally, screened porches and patios were recommended to allow passive cooling by ventilation. This is while preventing insect's penetrations. According to [11], insect screens are particularly desirable in the tropics. This is also to protect occupants from serious illnesses such as Malaria and Dengue Fever.

There are other recommended strategies that will certainly help in improving the ventilation of a house for thermal comfort and passive design consideration. However, it was not possible to provide all the recommendations in the article. 
However, a few suggested recommendations may not necessary work well in the humid tropics such designing a house with low pitch roof. This is due to the intensive rainfall in the equatorial humid tropics of Malaysia.

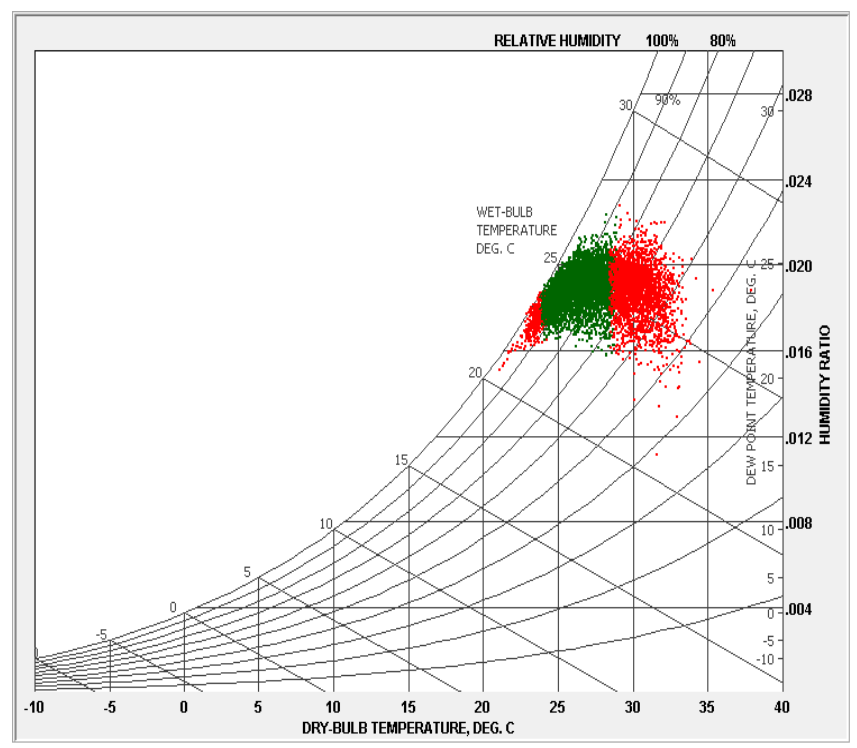

Fig. 8. Psychometric chart adaptive comfort.

A pitched roof is highly recommended in Kota Kinabalu. Further, the wind speed is moderate. It is important to mention that many possible strategies for passive housing design in the humid tropics were not recommended in Climate Consultant, Mahoney tables and bioclimatic chart. Those require further investigations. For instance, in the past, in Brunei traditional ethnic house of Malaysia, the main door of the house was facing the rising sun [13]. It was attributed to the people beliefs. This was used as well to ensure good health of the occupant. It might be explained by this, in the absence of the rising sun, the high humidity level may affect negatively people heath. Further according to reference [8], it was reported that generally buildings in humid climates are subjected to intense attack by insects, and materials rust and decay than in other environments [8]. This might further justify the importance of exposing the house to direct sun radiation in the absence of wind. It is important to mention that specifications for thermal design recommendations depend also on the location of the site.

\section{CONCLUSION}

This investigation is about passive cooling strategies in the equatorial humid tropics for indoor thermal comfort. Three methods were used in this study. The three methods agreed that ventilation is the best recommended strategy for indoor passive cooling. This is while considering occupants thermal comfort. Permanent air movement was recommended when planning and constructing building. Rooms should be single banked.

The openings should also be $40-80 \%$ of the wall area at body height side. It should be well protected from direct sunlight. Light insulated roofs with reflective surface should be ensured under Kota Kinabalu climate. Protection from heavy rain is necessary and adequate rainwater drainage was also recommended. Door and window openings should be selected to be on opposite sides of building. Screened porches and patios were recommended to allow passive cooling by ventilation. This is while preventing insect's penetrations. Other important observations and suggestions were also made by the author of the present article.

\section{REFERENCES}

[1] O. H. Koenigsberger, T. G. Ingersoll, A. Mayhew, and S. V. Szokolay, Manual of Tropical Housing and Building: Climatic Design, Hyderabad, India: Orient Longman, 1973.

[2] H. Djamila, C. C. Ming, and S. Kumaresan, "Field study for prediction and evaluation of thermal comfort in residential buildings in the equatorial hot humid climate of Malaysia," Building and Environment, vol. 62, pp. 133-142, 2013.

[3] R. Dear, K. G. Leow, and S. C. Foo, "Thermal comfort in the humid tropics: field experiments in air-conditioned and naturally ventilated buildings in Singapore," Int J Biometeorol, vol. 34, pp. 259-265, 1991.

[4] MS 1525 Code of Practice on Energy Efficiency and Use of Renewable Energy for Non-residential Buildings, Malaysian Standard-2001.

[5] A. H. Mahmouda, "An analysis of bioclimatic zones and implications for design of outdoor built environments in Egypt," Building and Environment, vol. 46, pp. 605-620, 2011.

[6] G. Z. Brown, Sun, Wind and Light, New York: John Wiley and Sons. Inc., 1985.

[7] B. Givoni, Passive and Low Energy Cooling of Building, New York: Van Nostrand Reinfold, 1994.

[8] P. Stouter, Shaping Building for the Hamid Tropics: Culture, Climate and Materials, American Society of Landscape Architects, 2008.

[9] T. Chenvidyakarn, "Passive design for thermal comfort in hot humid climates," Journal of Architectural Planning Research and Studies, vol. 5, pp. 3-27, 2007.

[10] E. Prianto and P Depecker1, "Optimization of architectural design elements in tropical humid region with thermal comfort approach," Energy and Buildings, pp. 273-280, 2003.

[11] R. Aynsley, Natural Ventilation in Passive Design, Australian: The Royal Australian Institute of Architects, 2007.

[12] ASHRAE Standard 55, Thermal Environmental Conditions for Human Occupancy, Atlanta, USA: Refrigerating and Air-Conditioning Engineers, 2010.

[13] A. H. Taha et al., Rumah Tradisional Etnik Sabah: Sabah Traditional Ethnic Houses, Malaysia, Sabah: Department of Sabah Museum, 2007.

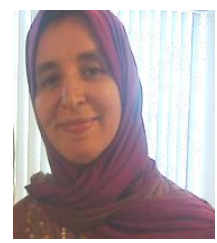

Harimi Djamila received the $\mathrm{PhD}$ award in science (Faculty of Engineering ex S.K.T.M.) at the Universiti Malaysia Sabah in 2013. Currently, she is a senior lecturer at the same university. Her area of research includes thermal comfort and housing passive cooling. 